This item was submitted to Loughborough's Research Repository by the author.

Items in Figshare are protected by copyright, with all rights reserved, unless otherwise indicated.

\title{
Preface to the special issue on "Loess engineering properties and loess geohazards"
}

PLEASE CITE THE PUBLISHED VERSION

https://doi.org/10.1016/j.enggeo.2017.11.017

\section{PUBLISHER}

(c) Elsevier

\section{VERSION}

AM (Accepted Manuscript)

\section{PUBLISHER STATEMENT}

This work is made available according to the conditions of the Creative Commons Attribution-NonCommercialNoDerivatives 4.0 International (CC BY-NC-ND 4.0) licence. Full details of this licence are available at: https://creativecommons.org/licenses/by-nc-nd/4.0/

\section{LICENCE}

CC BY-NC-ND 4.0

\section{REPOSITORY RECORD}

Peng, Jianbing, Shengwen Qi, Ann Williams, and Tom Dijkstra. 2019. "Preface to the Special Issue on "loess Engineering Properties and Loess Geohazards"”. figshare. https://hdl.handle.net/2134/32004. 


\title{
Preface to the special issue on "Loess engineering properties and loess geohazards"
}

\author{
Jianbing Peng ${ }^{\mathrm{ab}}$, Shengwen Qij ${ }^{\text {cde }}$, Ann Williams ${ }^{\mathrm{f}}$, Tom Dijkstrag \\ ${ }^{a}$ Department of Geological Engineering, Chang'an University, Xi'an 710054, Shaanxi, China \\ ${ }^{b}$ Key Laboratory of Western China Mineral Resources and Geological Engineering, Ministry of \\ Education of China, Xi'an 710054, Shaanxi, China \\ ${ }^{c}$ Key Laboratory of Shale Gas and Geoengineering, Institute of Geology and Geophysics, Chinese \\ Academy of Sciences, Beijing 100029, China \\ ${ }^{d}$ Institutions of Earth Science, Chinese Academy of Sciences, Beijing 100029, China \\ e University of Chinese Academy of Sciences, Beijing 100049, China \\ ${ }^{f}$ Beca Ltd., P.O. Box 6345, Auckland, New Zealand \\ ${ }^{g}$ School of Architecture, Building and Civil Engineering, Loughborough University, Loughborough \\ LE11 3TU, United Kingdom
}

\section{Introduction}

Loess is a Quaternary sediment that is widely distributed in arid and semi-arid regions. In China, loess deposits cover an area of approximately $630,000 \mathrm{~km} 2$, or some $4.4 \%$ of China's total land area, making up $20 \%$ of arable land and supporting $17 \%$ of its population (Zhang, 1993). Land for development is in short supply in these loess areas and therefore, in recent years, local governments have promoted projects that remove the tops of mountains to fill in valleys to create land that can more readily be developed (Li et al., 2014). Meanwhile, loess has a special structure, and properties that include high water sensitivity and collapsibility (Lutenegger, 1981; Gao, 1988). As a result, many geohazards and engineering challenges occur in loess lands, e.g. landslides, erosion and collapsible settlement (Derbyshire et al., 2000; Xu et al., 2014; Peng et al., 2017, 2015). The engineering geological problems of loess have attracted extensive research in past decades.

In 1988, Engineering Geology published a special issue titled 'Loess Geotechnology'. Since then, almost thirty years have passed, and important advances have been achieved in, for example, field monitoring, physical modeling, evaluation of the mechanical properties of loess, theoretical analyses and numerical simulations, that are significant to understanding loess hazard distribution, characteristics, trigger factors, mechanisms, assessment and forecasting. The guest editors believed there was a need to organize a special issue on "loess engineering properties and loess geohazards". This special issue aims to bring together findings from ongoing research and engineering practices in loess terrains in different parts of the world, providing an insight into the state-of-the-art understanding of geological hazards in loess terrains, as well as document field and laboratory techniques and data that can be used to calibrate and validate new approaches.

A total of 35 papers were submitted with 13 being eventually accepted. These papers cover a variety of achievements, including geohazards investigation in loess terrain, laboratory experiments on the mechanical behavior of loess, and micro-structure analysis.

\section{Loess engineering properties}

Loess is formed by the accumulation of wind-blown fine sand, silt and clay, covering a diverse topography and varying geology. The aeolian deposition results in characteristic texture, fabric and structure creating meta-stable landforms that can fail catastrophically when wetted up, or when disturbed by seismic shock. Therefore, the special engineering properties of loess have attracted much attention from researchers. In this special issue, seven papers focus on the engineering properties of loess. 
There are two review papers on the mechanical properties of loess in China and New Zealand respectively. Li (2018) presents a thorough review of tensile and shear strengths of Malan Loess based on a great amount of literature. It is shown that strength decreases with water content and increases with dry density. The difference in structure between undisturbed and disturbed loess results in the strength difference. The shear strength variation of the loess demonstrates anisotropy, while tensile strength is influenced by numerous factors including test method, sample size and loading rate.

Loess and loess-derived soils cover much of Canterbury in the South Island of New Zealand. Yates et al. (2018) present a review of the geotechnical characteristics of loess and loess- derived soils from Canterbury. It seems that contrary to loess deposits in other parts of the world, the loess deposits in Canterbury do not display collapse behavior, mainly because these soils contain up to $45 \%$ clay resulting in low plasticity clay behavior and high density. These soils also have high dry strength but weaken rapidly with small increases in moisture content, leading to local variations in slope stability. In the wetter parts of the region, periodic wetting leads to a variety of slope failures related to internal erosion and rapid loss of shear strength that causing debris flows, soil slides and rotational failure. In drier parts of South Canterbury, loess deposits commonly form vertical exposures and evidence of slope instability is comparatively rare. Furthermore, macro-scale heterogeneities within the loess may also exhibit significant local variation. The effects of microstructure on soil behavior are also discussed, but have yet to be investigated in detail.

Two papers present research on the mechanical properties of two kinds of loess. Fan et al. (2018) examine the mechanical behavior of fissured loess on the basis of triaxial experiments. The confining pressure and dip direction of fissures are found to have a significant effect on the mechanical features of such type of loess. Additionally, the stress-strain relationship of fissured loess is analyzed via a double parameter binary-medium model, and the fitting results show that the presented model is suitable to model fissure development in loess.

Xu et al. (2018) study the mechanical behavior of saturated silty loess retrieved from the northwestern part of the Loess Plateau in China. Triaxial and oedometer tests are performed on intact and reconstituted samples in a saturated condition. The results show that the soil structure has a significant effect on the mechanical behavior, which is similar to the structured clayey loess from the southeastern Loess Plateau. The mechanical behavior of loess as observed in laboratory tests was then adopted to interpret the mechanisms of landslide initiation and movement. Two papers focus on the mechanical behavior and micro-structure of loess. Xie et al. (2018) carry out triaxial creep tests coupled with observations of microstructural changes in loess-derived soil samples collected in the Xi'an area of China. The particles and pore structure under different axial stress and confining pressures during the tests are recorded with a polarizing microscope. It is found that creep behavior of this soil is closely related micro-structural changes. The structure of the soil is analyzed during progressive creep, including observations on number, area, size, orientation, and shape of particles and pores.

Luo et al. (2018) report research achievements on the microstructure and macroscopic geotechnical properties of Malan loess. The triaxial and uniaxial compression tests are performed under humidifying conditions on undisturbed loess and micro-structural changes were observed using scanning electron microscopy. They find that the geotechnical properties of the top loess and basal loess are mainly dominated by metastable structure and inter-particles cementation bonds respectively. The microstructure observations show that the loess pore structure change is mainly attributed to the ratio of metastable pores $(>5 \mu \mathrm{m})$. An end-member model is proposed to illustrate the size and distribution variation of very large, large, medium and small sized of pores. The process of inter-particle bond loss caused by groundwater, pore collapse, pore pressure increase and shear 
strength loss is considered to explain the mechanism of accelerated movement of the Zhaojiaan landslide in northern Shaanxi, China.

One paper carries out research on the saturated hydraulic conductivity of a loess slope located in the South Jingyang Plateau, China (Wang et al., 2018). The variable head permeability tests are conducted on loess samples collected from a trench and an adit within the slope. Results show that the loess exhibits anisotropic permeability. Lilliefors test results indicate that the saturated horizontal hydraulic conductivity (Kh) and saturated vertical hydraulic conductivity (Kv) mostly show a log normal distribution, although some showed a normal distribution. The hydraulic conductivities tend to decrease with depth and can be described by an exponential decay model. The authors find that the loess structure is the dominant reason for the spatial variation of the saturated hydraulic conductivity.

\section{Loess geohazards}

Loess related geohazards bring about serious human loss, damage to gas and oil pipelines, destruction of roads and railways, as well as loss of farmland. Six papers conduct research on Loess Geohazards in this special issue.

Three papers describe the spatial distribution of particular types of geohazards. Peng et al. (2018b) introduce geological hazards associated with loess caves. Numerous investigations carried out in the Chinese Loess Plateau enable them to characterize and classify loess cave geohazards. The regional development of this geohazard is studied and the main factors controlling the development of loess caves are analyzed.

Zhuang et al. (2018) performed field investigations and monitoring, in-situ tests and laboratory experiments to study the distribution and characteristics of loess landslides in Shaanxi Province, China. Three factors incorporating scale, morphology and equivalent friction coefficient of loess landslides are analyzed statistically. Moreover, factors resulting in clusters of landslides in the Chinese Loess Plateau are discussed from the perspective of loess structure and mechanical behavior, as well as the antecedent rainfall.

Peng et al. (2018a) analyze the distribution and failure modes of landslides occurring in the Heitai terrace (Gansu Province, China) based on the interpretation of aerial images, a Digital Elevation Model and field investigations. The geological structure, distribution, and characteristics of 69 landslides are studied, and two types of landslides, loess landslides and loess-bedrock landslides, are distinguished and analyzed.

Three papers present typical case studies of loess geohazards. Leng et al. (2018) introduce a fluidized landslide occurred in South Jinyang tableland located in the southern part of the Chinese Loess Plateau. Around $20,000 \mathrm{~m} 3$ of loess rapidly slid from a $65 \mathrm{~m}$ high slope travelling some $260 \mathrm{~m}$. The moisture content test results show that the degree of water saturation in the landslide depression was relatively high, and the leading edge was in a flow state. The field investigation indicates that strength loss at the toe of the slope induced by irrigation is the major factor contributing to slope movement. Laboratory experiments of undrained triaxial shear tests on loess with a variety of water contents were also carried out and the results showed that the higher saturation both weakened the loess strength and increased the pore water pressure. The authors indicate that the motion mechanism of this high-speed and long-runout landslide may be attributed to liquefaction of the loess resulting in shear strength loss during movement. The Heifangtai terrace, located in the loess area in Gansu Province (China) is well known for developing a large number of landslides induced by agricultural irrigation. As a result, the slopes on the margin of the terrace retreat at a rate of 0.024 $\mathrm{km}^{2}$ per year. 
Qi et al. (2018) report on extensive research on the retrogressive loess flowslides along the Heifangtai terrace, including field investigation and monitoring, remote sensing and aerial images and laboratory tests. The characteristics of slope retreat and the failure mechanism of the loess flowslides are analyzed. The results show that slope retreat is caused by the retrogressive failure. The groundwater level variation governs the failure process and mechanism. Isotropically consolidated, undrained triaxial tests (ICU) and constant shear stress, drained triaxial tests (CSD) reveal the strain softening behavior of saturated, reconstituted loess. Changes in microstructure are used to explain the excess porewater pressure associated with axial displacement.

Finally, Zhang and Wang (2018) conduct research on the mechanism of flowslides occur in the Heifangtai terrace. They perform a series of undrained ring shear tests on loess samples from the source area of a landslide in the Heifangtai terrace to examine the undrained shear behaviors of these samples at differing initial void ratios. Results show that all these tested samples exhibited purely contractive behavior throughout the entire undrained shearing process. The relationship between mechanical properties and void ratio are analyzed (focusing on pore-water pressure, peak and steady-state shear strength and brittleness index). These analyses enable them to reach the conclusion (also arrived at by Leng et al.), that the irrigation-induced collapse of the loess structure is the key factor for the initiation and mobility of flowslides occurring along the margins of the Heifangtai terrace. The hydraulic conductivity of the loess plays an important role in the water infiltration induced landslides.

\section{Acknowledgements}

This special issue would have not been possible without the effort of many individuals. The guest editors owe gratitude to all the contributing authors of the $\mathrm{SI}$, to the efforts of our dedicated reviewers, and to Harinath Subramaniam (the past Journal Manager), Shruti Venkiteswaran (the current Journal Manager), and Emily Wan (the Special Issue Manager) for their assistance. Finally, but not the least, we would like to thank the Editor in Chief of Engineering Geology, Professor Hsein Juang, for giving us the opportunity to host this Special Issue in this prestigious Journal and for his guidance and support during the course of this project.

\section{References}

E. Derbyshire, X.M. Meng, T.A. Dijkstra (Eds.) 2000. Landslides in the Thick Loess Terrain of Northwest China: Mechanisms and Mitigation, John Wiley and Sons, Ltd., Chichester, 288 pp.

W. Fan, L. Deng, W. Yuan 2018. Double parameter binary-medium model of fissured loess. Eng. Geol. This issue.

G. Gao 1988. Formation and development of the structure of collapsing loess in China. Eng. Geol., 25 (2-4), pp. 235-245

Y. Leng, J. Peng, Q. Wang, Z. Meng, W. Huang 2018. A fluidized landslide occurred in the Loess Plateau: a study on loess landslide in South Jingyang tableland. Eng. Geol. This issue.

P. Li, H. Qian, J. Wu 2014. Environment: accelerate research on land creation. Nature, 510 (7503), pp. 29-31

Y. Li 2018. A review of shear and tensile strengths of the Malan Loess in China. Eng. Geol. This issue.

H. Luo, F. Wu, J. Chang, J. Xu 2018. Microstructural constraints on geotechnical properties of Malan Loess: a case study from Zhaojiaan landslide in Shaanxi province, China. Eng. Geol. This issue.

A.J. Lutenegger 1981. Stability of loess in light of the inactive particle theory. Nature, 291 (5813), p. 360

D. Peng, Q. Xu, F. Liu, Y. He, S. Zhang, X. Qi, K. Zhao, X. Zhang 2018. Distribution and failure modes of the landslides in Heitai terrace, China. Eng. Geol. This issue. 
J. Peng, Z. Fan, D. Wu, J. Zhuang, F. Dai, W. Chen, C. Zhao 2015. Heavy rainfall triggered loessmudstone landslide and subsequent debris flow in Tianshui, China. Eng. Geol., 186, pp. 79-90

J. Peng, P. Sun, I. Ogbonnaya, X. Li 2018. Loess caves, a special kind of geo-hazard on loess plateau, northwestern China. Eng. Geol. This issue.

J. Peng, G. Wang, Q. Wang, F. Zhang 2017. Shear wave velocity imaging of landslide debris deposited on an erodible bed and possible movement mechanism for a loess landslide in Jingyang, Xi'an, China. Landslides, 14 (4), pp. 1503-1512

X. Qi, Q. Xu, F. Liu 2018. Analysis of retrogressive loess flowslides in Heifangtai, China. Eng. Geol. This issue.

W. Wang, Y. Wang, Qi Sun, M. Zhang, Y. Qiang, M. Liu 2018. Spatial variation of saturated hydraulic conductivity of a loess slope in the South Jingyang Plateau, China. Eng. Geol. This issue.

X. Xie, S. Qi, F. Zhao, D. Wang 2018. Creep behavior and the microstructural evolution of loess-like from Xi'an area, China, Eng. Geol. This issue.

L. Xu, F. Dai, X. Tu, et al. 2014. Landslides in a loess platform, North-West China. Landslides, 11 (6), pp. 993-1005

L. Xu, M. Coop, M. Zhang, G. Wang 2018. The mechanics of a saturated silty loess and implications for landslides. Eng. Geol.

K. Yates, C. Fenton, D. Bell 2018. A review of the geotechnical characteristics of loess and loessderived soils from Canterbury, South Island, New Zealand. Eng. Geol. This issue.

T. Zhang 1993. Contention of Key Issues in China's Loess Plateau. China Environmental Science Press. (in Chinese)

F. Zhang, G. Wang 2018. Effect of irrigation-induced densification on the post-failure behavior of loess flowslides occurring on the Heifangtai area, Gansu, China. Eng. Geol. This issue.

J. Zhuang, J. Peng, G. Wang, I. Javed, Y. Wang, W. Li 2018. Distribution and characteristics of landslide in loess plateau: a case study in Shaanxi province. Eng. Geol. This issue. 